\title{
Early Detection of Type II Ovarian Cancer with Labelled Microbubble Transvaginal Sonography
}

\author{
Audris Pinkerton ${ }^{1}$ and Arthur Fleischer ${ }^{2^{*}}$ \\ ${ }^{1}$ Meharry Medical College, USA \\ ${ }^{2}$ Department of Radiology and Obstetrics and Gynecology, Vanderbilt University Medical Center, USA
}

Submission: June 02, 2017; Published: June 22, 2017

*Corresponding author: Arthur Fleischer, Department of Radiology and Obstetrics and Gynecology, Vanderbilt University Medical Center, USA, Email: arthur.fleischer@Vanderbilt.Edu

Abstract

Ovarian cancer is the most lethal of all gynecological malignancies. However early detection can potentially improve the survival rate from 50 to $90 \%$. Transvaginal sonography with the use of contrast-enhanced microbubbles has shown promise when used to detect malignant ovarian lesions in several studies [1-3]. This brief communication addresses the need and potential benefits of contrast enhanced transvaginal sonography, as well as directions for future research and clinical applications.

\section{Introduction}

Ovarian cancer is the seventh most common cancer in women and the most lethal of all gynecological malignancies in the United States. Each year, more than 22,000 patients are diagnosed with ovarian cancer and 14,000 cancer related deaths are reported [4]. Often presenting with subtle and nonspecific symptoms, ovarian cancer is first diagnosed at advanced stages leading to poorer prognoses. However, early detection can significantly increase the survival rate from 50 to $90 \%$. Earlier diagnosis and cancer confinement to the ovary can lead to much more favorable outcomes for patients [3]. One method to facilitate early detection is through screening, but currently available tools, such as biomarkers and imaging, lack sensitivity and specificity for certain ovarian tumors in early and more treatable stages.

Ovarian cancer is classified into type I and II [5]. Type I carcinomas, most common in Asia, are slow growing, indolent neoplasms that typically arise from a precursor lesion. These include endometrioid carcinoma, clear cell carcinoma, mucinous carcinoma, and low-grade serous carcinoma. Type II carcinomas, most common in the USA and Europe, are clinically aggressive neoplasms that develop from ovarian surface epithelium and/ or de novo from serous tubal intraepithelial carcinomas (STIC). These include high-grade serous carcinomas and are associated with genetic instability, TP53 gene mutations, BRCA 1 and 2 mutations, and high Ki67 proliferation index. Thus theoretically, based on growth patterns, annual screening with transvaginal sonography and CA125 alone would be more effective in Asia (predominantly type I cancers) than in the USA and Europe (predominantly type II cancers) [5]. Although there has been successful detection of these lesions in animal studies, early detection of type II ovarian cancer remains a challenge $[3,5]$.

\section{Transvaginal microbubble sonography}

Sonography is a non-invasive imaging technique that allows for the real-time evaluation of the region of interest, including functional information on tissue vascularity, and is currently the preferred first-line method of imaging suspicious breast and ovarian lesions. Sonography is widely available, inexpensive, and portable. However, transvaginal sonography lacks sensitivity and specificity for the detection of tumors in early stages. Targeted sonography is the application of targeted contrast agents during ultrasound procedures to image specific biomarkers with many clinical applications including diagnostic imaging, gene and drug therapy delivery, blood flow mapping, selective endothelial receptor imaging, and more. Microbubbles are tiny bubbles used as contrast agents in ultrasound diagnostic procedures. Typically, microbubbles are filled with per fluorocarbon gas inside an outer lipoprotein shell. They are useful because of their small size, 1-7 micron-diameter, and their circulating movements in vasculature, very similar to that of erythrocytes, allowing their utilization to detect neoplastic growth. Microbubbles, injected intravenously, remain purely intravascular in comparison with contrast agents used for MRI and CT exams. They remain in vasculature until the lipoprotein shells are metabolized by the liver and the encapsulated gas is eliminated via the lungs 5-7 
minutes after injection. Imaging techniques using microbubble contrast provide quantitative information about blood passage through the capillaries within tissues. Signals acquired from microbubbles can be used to estimate blood flow and quantify abnormal changes which may result from occluded vessels in body tissues and abnormal vasculature as in neoplastic growths. Targeted microbubbles have ligands that attach to endothelial cell surface receptors up regulated in cancer, such as vasogenic epithelial growth factor/VEGF (Figure 1). Transvaginal targeted microbubble sonography provides better characterization, improved detection, and monitoring of cancer in preliminary studies [5]. Contrast enhanced microbubble transvaginal sonography have shown improved accuracy for detection when compared to 2D and 3D Doppler Transvaginal Sonography [6-8].

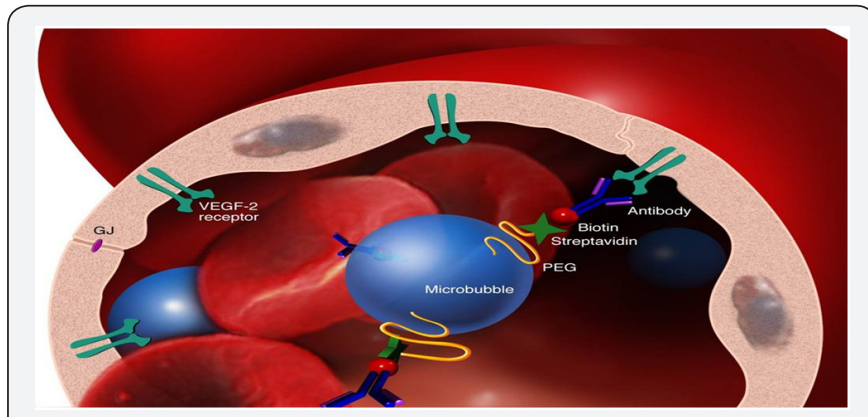

Figure 1: VEGF-targeted microbubble coated with BiotinStreptavidin complex for improved biomarker binding. GJ: Gap Junction, VEGF: Vasogenic Epithelial Growth Factor; PEG: Polyethylene Glycol.

\section{Success thus far}

To date, microbubbles have not been associated with any untoward effects after preliminary studies in millions of patients across the world. In fact, in 2016, the FDA approved the use of Lumason, a microbubble contrast, for improved liver lesion characterization. Microbubbles are also being used in pediatric patients who receive blunt trauma with imaging of the kidneys, spleen, liver and pancreas. Initial studies have demonstrated significant differences in vascular enhancements of benign versus malignant masses [1-3]. Although contrast-enhanced transvaginal sonography cannot distinguish between borderline and malignant masses, both require surgical intervention [3]. In addition, compared to no screening, transvaginal sonography has been associated with an overall $20 \%$ mortality reduction in a large prospective study involving over 250,000 women [8].

\section{Potential Applications}

Ovarian cancer screening efficacy depends on the cancer subtype [4]. Transvaginal sonography with the use of contrastenhanced microbubbles can be further studied using different biomarkers, more specifically for type II ovarian cancers. It has also shown promise in preliminary studies and could ultimately become part of ovarian cancer screening secondary to initial assessments. Recent FDA approval will likely lead to further clinical use of microbubbles as contrast agents for various sonography studies. Theranostic applications, which combine a biomarker target and enhanced drug delivery, may be possible in the near future [6].

\section{References}

1. Fleischer, Arthur C (2010) Advances in sonographic detection of ovarian cancer: depiction of tumor neovascularity with microbubbles. AJR Am J Roentgenol 194(2): 343-348.

2. Willmann JK, Bonomo L, Testa AC, Rinaldi P, Rindi G, et al. (2017) Ultrasound molecular imaging with br55 in patients with breast and ovarian lesions: first-in-human results. Journal of Clinical Oncology 35.

3. Fleischer AC (2016) Early detection of ovarian cancer with transvaginal microbubble sonography: current and potential applications. Current Trends in Gynecologic Oncology 1: 2.

4. Fleischer AC, Lyshchik A, Hirari M, Moore R, Abramson RG, et al. (2012) Early detection of ovarian cancer with conventional and contrastenhanced transvaginal sonography: recent advances and potential improvements. J Oncol doi: 10.1155/2012/302858.

5. Koshiyama M, Matsumura N, Konishi I (2017) Subtypes of ovarian cancer and ovarian cancer screening. Diagnostics 7(1): 12.

6. Fleischer AC, Lyshchik A, Caskey C (2016) Theranostic applications of microbubble sonography in oncology. Clinics in Oncology 1: 1010.

7. Barua A, Bitterman P, Bahr J, Bradaric MJ, Hales DB, et al. (2010) Detection of tumor associated neoangiogenesis by doppler ultrasound during early-stage ovarian cancer in laying hens: a preclinical model of human spontaneous ovarian cancer. J Ultra Med 29(12):0020173-182.

8. Jacobs IJ, Menon U, Ryan A, Gentry-Maharaj A, Burnell M, et al. (2015) Ovarian Cancer screening and mortality in the UK collaborative trial of ovarian cancer screening (UKCTOCS): a randomized controlled trial. Lancet Online 387(10022): 945-956.

Your next submission with Juniper Publishers
will reach you the below assets
- Quality Editorial service
- Swift Peer Review
- Reprints availability
- E-prints Service
- Manuscript Podcast for convenient understanding
- Global attainment for your research
- Manuscript accessibility in different formats
( Pdf, E-pub, Full Text, Audio)
- Unceasing customer service
Track the below URL for one-step submission
https://juniperpublishers.com/online-submission.php

